\title{
Prediction of lymph node metastasis by tumor-infiltrating lymphocytes in T1 breast cancer
}

\author{
Koji Takada', Shinichiro Kashiwagi ${ }^{1 *}$ D, Yuka Asano1, Wataru Goto', Rika Kouhashi', Akimichi Yabumoto', \\ Tamami Morisaki ${ }^{1}$, Masatsune Shibutani ${ }^{2}$, Tsutomu Takashima ${ }^{1}$, Hisakazu Fujita ${ }^{3}$, Kosei Hirakawa ${ }^{1,2}$ and \\ Masaichi Ohira, ${ }^{1,2}$
}

\begin{abstract}
Background: Lymph node metastasis is more likely in early-stage breast cancer with lower tumor-infiltrating lymphocyte (TIL) density. Therefore, we investigated the correlation between TILs and lymph node metastasis in CT1 breast cancer patients undergoing surgery and the usefulness of TILs in predicting sentinel lymph node metastasis (SLNM) in CT1NOMO breast cancer.

Methods: We investigated 332 breast cancer patients who underwent surgery as the first-line treatment after preoperative diagnosis of CT1. A positive diagnosis of SLNM as an indication for axillary clearance was defined as macrometastasis in the sentinel lymph node (SLN) (macrometastasis: tumor diameter $>2 \mathrm{~mm}$ ). Semi-quantitative evaluation of lymphocytes infiltrating the peritumoral stroma as TILs in primary tumor biopsy specimens prior to treatment was conducted.

Results: For SLN biopsy (SLNB), a median of 2 (range, 1-8) SLNs were pathologically evaluated. Sixty cases (19.4\%) of SLNM (macrometastasis: 46, micrometastasis: 16) were observed. Metastasis was significantly greater in breast cancers with tumor diameter $>10 \mathrm{~mm}$ than in those with diameter $\leq 10 \mathrm{~mm}(p=0.016)$. Metastasis was significantly associated with lymphatic invasion $(p<0.001)$. These two clinicopathological factors correlated with SLNM even in patients diagnosed with $\mathrm{cNO}$ (tumor size; $p=0.017$, lymphatic invasion; $p=0.002$ ). Multivariate analysis for SLNM predictors revealed lymphatic invasion $(p=0.008$, odds ratio $[O R]=2.522)$ and TILs $(p<0.001, O R=0.137)$ as independent factors.
\end{abstract}

Conclusions: Our results suggest a correlation between lymph node metastasis and tumor immune-microenvironment in CT1 breast cancer. TLL density may be a predictor of SLNM in breast cancer without lymph node metastasis on preoperative imaging.

Keywords: Breast cancer, Tumor-infiltrating lymphocytes, Tumor immune-microenvironment, Lymph node metastasis, Sentinel lymph node

\footnotetext{
* Correspondence: spqv9ke9@view.ocn.ne.jp

'Department of Breast and Endocrine Surgery, Osaka City University

Graduate School of Medicine, 1-4-3 Asahi-machi, Abeno-ku, Osaka 545-8585,

Japan

Full list of author information is available at the end of the article
}

(c) The Author(s). 2020 Open Access This article is licensed under a Creative Commons Attribution 4.0 International License, which permits use, sharing, adaptation, distribution and reproduction in any medium or format, as long as you give appropriate credit to the original author(s) and the source, provide a link to the Creative Commons licence, and indicate if changes were made. The images or other third party material in this article are included in the article's Creative Commons licence, unless indicated otherwise in a credit line to the material. If material is not included in the article's Creative Commons licence and your intended use is not permitted by statutory regulation or exceeds the permitted use, you will need to obtain permission directly from the copyright holder. To view a copy of this licence, visit http://creativecommons.org/licenses/by/4.0/ The Creative Commons Public Domain Dedication waiver (http://creativecommons.org/publicdomain/zero/1.0/) applies to the data made available in this article, unless otherwise stated in a credit line to the data. 


\section{Background}

Breast cancer frequently metastasizes to the axillary lymph nodes, and the status of axillary lymph nodes metastasis is a prognostic factor in early breast cancer. Sentinel lymph node (SLN) biopsy (SLNB) is commonly used for pathological evaluation even if axillary lymph node metastasis is not detected on imaging. SLNB is considered a minimally invasive method based on the results of previously reported randomized controlled trials $[1,2]$. However, in recent years, SLNB is being considered excessively invasive for breast cancer patients with a small primary tumor because it is unlikely to have metastasized [3]. Therefore, clinical trials that omit SLNB for $\mathrm{cNO}$ breast cancer patients diagnosed by ultrasonography (US) are underway $[4,5]$. One of the prospective randomized trials targeted $\mathrm{cT} 1$ breast cancer patients and the other trial targeted small primary tumor that could be resected with breast-conserving surgery. However, to summarize the previous reports, the SLN metastasis (SLNM) rate in T1 breast cancer was 18.8-29.6\%, which is substantial [6-10]. These studies have additionally reported various predictors of SLNM.

The tumor microenvironment, comprising cancerassociated fibroblastic cells, angiogenic vascular cells, and infiltrating immune cells, is strongly involved in cancer invasion and metastasis [11, 12]. Among these cells, lymphocytes around tumors, the so-called "tumorinfiltrating lymphocytes (TILs)", are used as a simple indicator of tumor-related immune response. It has been suggested that TILs may also affect cancer invasion and metastasis [11]. However, in breast cancer, TILs are strongly affected by the subtype of breast cancer. Hormone receptor-negative breast cancers such as human epidermal growth factor receptor 2 (HER2)-enriched breast cancer (HER2-enriched BC) and triple-negative breast cancer (TNBC) are known to have higher TIL density than hormone receptor-positive breast cancers $[13,14]$.

Therefore, we hypothesized that lymph node metastasis is likely to occur in breast cancer with lower TIL density. If this hypothesis is correct, we can also hypothesize that TILs could be a predictor of SLNM. Since the tumor size is a strong predictor of SLNM, and a prospective randomized trial that omit SLNB for cT1N0 breast cancer patients is in progress, we investigated the correlation between TILs and lymph node metastasis in cT1 breast cancer patients undergoing surgery along with the usefulness of TILs in predicting SLNM for cT1N0M0 breast cancer in this study.

\section{Methods}

\section{Patients}

In this study, we included 332 breast cancer patients who had undergone surgery as the first-line treatment after preoperative diagnosis of cT1 from April 2007 to October 2015 at Osaka City University Hospital. In all patients, breast cancer was diagnosed pathologically by core-needle biopsy (CNB) or vacuum-assisted biopsy (VAB). The expressions of estrogen receptor (ER), progesterone receptor (PgR), HER2, and Ki67 in the biopsy tissue was determined immunohistologically. Subsequently, we classified breast cancer based on the results of immunohistological staining as follows: HER2enriched BC (ER-, PgR-, and HER2+); TNBC (negative for $\mathrm{ER}, \mathrm{PgR}$, and HER2); hormone receptor (HR) + HER2 + BC (hormone receptor and HER2-positive breast cancer; ER+ and/or PgR+, and HER2+); and $\mathrm{HR}+$ HER2-BC (hormone receptor-positive and HER2negative breast cancer; ER+ and/or PgR+, and HER2-). Based on previous reports, the cutoff value for Ki67 was considered to be $14 \%$ [15]. US, computed tomography $(\mathrm{CT})$, and bone scintigraphy were performed to rule out distant metastasis. All patients underwent mastectomy or breast-conserving surgery. In patients in whom axillary lymph node metastasis was suspected on imaging, axillary lymph node dissection was performed. In contrast, in patients in whom metastasis to the lymph nodes was not suspected, SLNB was performed. The SLN was identified using a combination of radioisotope and dye methods, as per previous reports [16, 17]. SLNs were sliced into 2-mm-thick slices and pathologically examined for metastases [18, 19]. SLNM was classified according to previous reports; (Macrometastasis: tumor diameter $>2 \mathrm{~mm}$. Micrometastasis: tumor diameter $>0.2$ $\mathrm{mm}, \leq 2 \mathrm{~mm}$, or $<200$ tumor cells. Isolated tumor cells: tumor diameter $<0.2 \mathrm{~mm}$ or $<200$ tumor cells) [20].

\section{Histopathological evaluation of TIL density}

Histopathological evaluation of TIL density was performed in the biopsy specimens. The definition and evaluation of TIL were based on the International TILs working group 2014 guideline, which calculates the average density of the infiltrating lymphocytes within the tumor stroma in five randomly selected fields [21]. We defined 4 classes or scores according to TIL density according to previous reports; (score 3 ; >50\%, score 2 ; > 10 $50 \%$, score $1 ; \leq 10 \%$, or score 0 ; absent) (Fig. 1) [22, 23].

\section{Statistical analysis}

Statistical analyses were performed using JMP software package (SAS, Tokyo, Japan). To compare the distribution of TIL density according to the state of lymph node metastasis, we performed Student's t test. Pearson's chisquare test was used to evaluate the correlation between two groups based on clinicopathological features. Odds ratios (ORs) and 95\% confidence intervals (CIs) were calculated using logistic regression analysis. Multivariable analysis was performed using the multivariable 


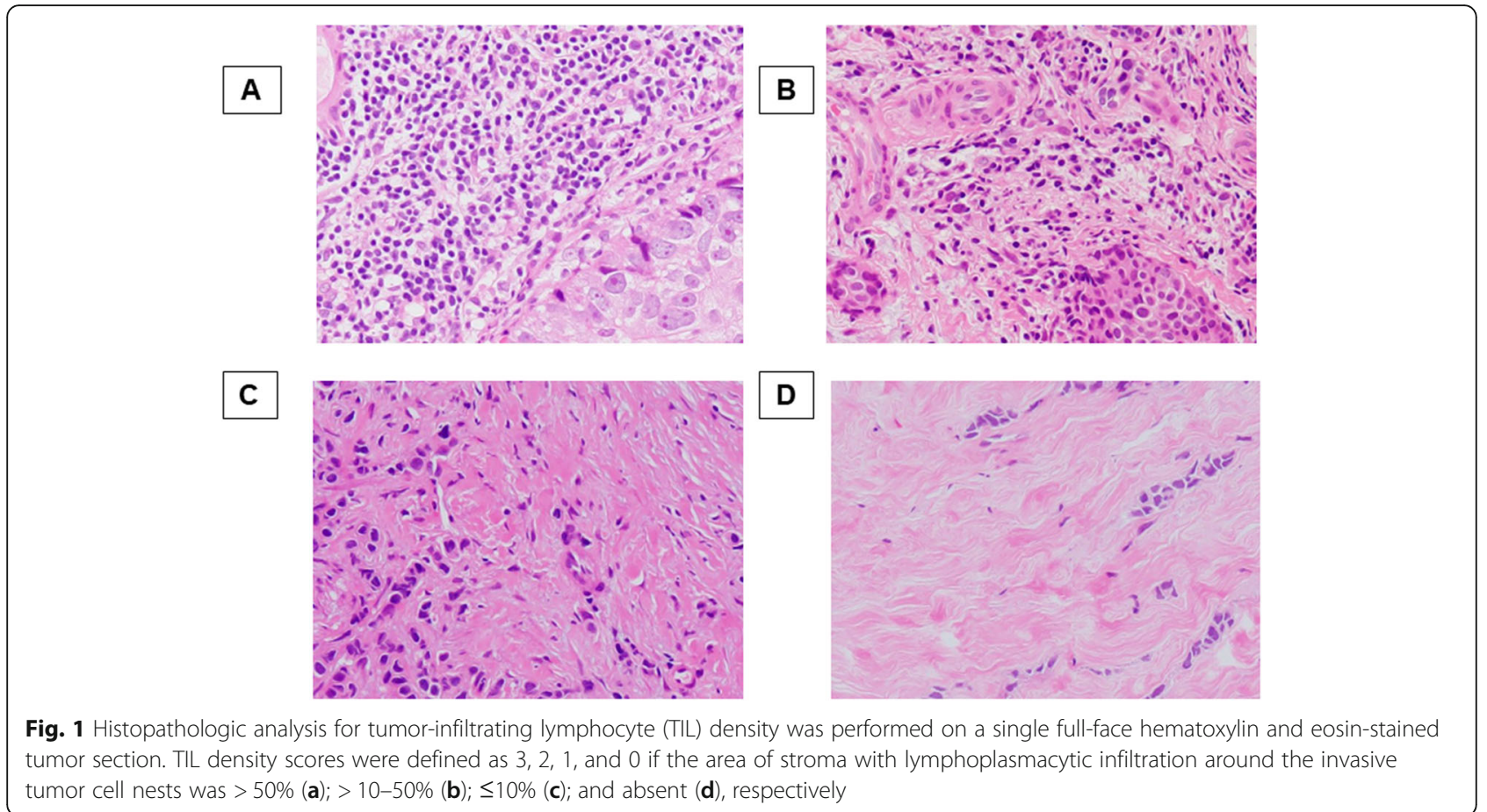

Table 1 Clinicopathological features of 332 patients who had surgery after being diagnosed with cT1N0-2 M0 breast cancer, including 319 cT1NOMO breast cancer

\begin{tabular}{|c|c|c|}
\hline Parameters & $\begin{array}{l}\text { Number of all patients } \\
(n=332)(\%)\end{array}$ & $\begin{array}{l}\text { Number of } \mathrm{cNO} \text { patients } \\
(n=319)(\%)\end{array}$ \\
\hline Age at operation (years old) & median 59 (range, 29-79) & median 59 (range, 29-79) \\
\hline Tumor size (mm) & median 13 (range, 4-20) & median 13 (range, 4-20) \\
\hline Clinical lymph node metastasis cN0 / cN1 / cN2 & 319 (96.1\%) / 11 (3.3\%) / 2 (0.6\%) & - \\
\hline Estrogen receptor Negative / Positive & $59(17.8 \%) / 273(82.2 \%)$ & $57(17.9 \%) / 262(82.1 \%)$ \\
\hline Progesterone receptor Negative / Positive & $130(39.2 \%) / 202(60.8 \%)$ & 125 (39.2\%) / 194 (60.8\%) \\
\hline HER2 Negative / Positive & $306(92.2 \%) / 26(7.8 \%)$ & $295(92.5 \%) / 24(7.5 \%)$ \\
\hline Ki67 $\leq 14 \% />14 \%$ & $206(62.0 \%) / 126(38.0 \%)$ & 196 (61.4\%) / 123 (38.6\%) \\
\hline \multirow{2}{*}{$\begin{array}{l}\text { Intrinsic subtype HR + HER2-BC / HR } \\
+ \text { HER2 + BC / HER2enriched BC / TNBC }\end{array}$} & $265(79.8 \%) / 11(3.3 \%) / 15$ & $255(79.9 \%) / 10(3.1 \%) / 14$ \\
\hline & $(4.5 \%) / 41(12.4 \%)$ & $(4.4 \%) / 40(12.6 \%)$ \\
\hline Lymphatic invasion ly0 / ly1 & $229(69.0 \%) / 103(31.0 \%)$ & $224(70.2 \%) / 95$ (29.8\%) \\
\hline Venous invasion v0 / v1 & $318(95.8 \%) / 14(4.2 \%)$ & $306(95.9 \%) / 13(4.1 \%)$ \\
\hline \multirow[t]{2}{*}{ Nuclear grade $1 / 2$ / 3} & $164(49.4 \%) / 129(38.9 \%) / 39$ & 158 (49.5\%) / 125 (39.2\%) / 36 \\
\hline & $(11.7 \%)$ & $(11.3 \%)$ \\
\hline \multirow{2}{*}{$\begin{array}{l}\text { Pathological lymph node metastasis } \\
\text { pN0 / pN1mic / pN1a / pN2 }\end{array}$} & $257(77.4 \%) / 16(4.8 \%) / 54$ & $257(80.6 \%) / 16(5.0 \%) / 46$ \\
\hline & $(16.3 \%) / 5(1.5 \%)$ & $(14.4 \%) / 0(0.0 \%)$ \\
\hline \multirow[t]{2}{*}{ TILs (score) $0 / 1 / 2 / 3$} & $29(8.7 \%) / 243(73.2 \%) / 57$ & $25(7.8 \%) / 235(73.7 \%) / 56$ \\
\hline & $(17.2 \%) / 3(0.9 \%)$ & $(17.6 \%) / 3(0.9 \%)$ \\
\hline
\end{tabular}

HER2: human epidermal growth factor receptor 2. HR + HER2-BC: hormone receptor-positive and HER2 negative breast cancer (ER+ and/or PgR+, and HER2-). HR + HER2 + BC: hormone receptor-positive and HER2 positive breast cancer (ER+ and/or PgR+, and HER2+). HER2 enriched BC: human epidermal growth factor receptor 2-enriched breast cancer (ER-, PgR-, and HER2+). TNBC: triple negative breast cancer (ER-, PgR-, and HER2-). TILs: tumor- infiltrating lymphocytes 


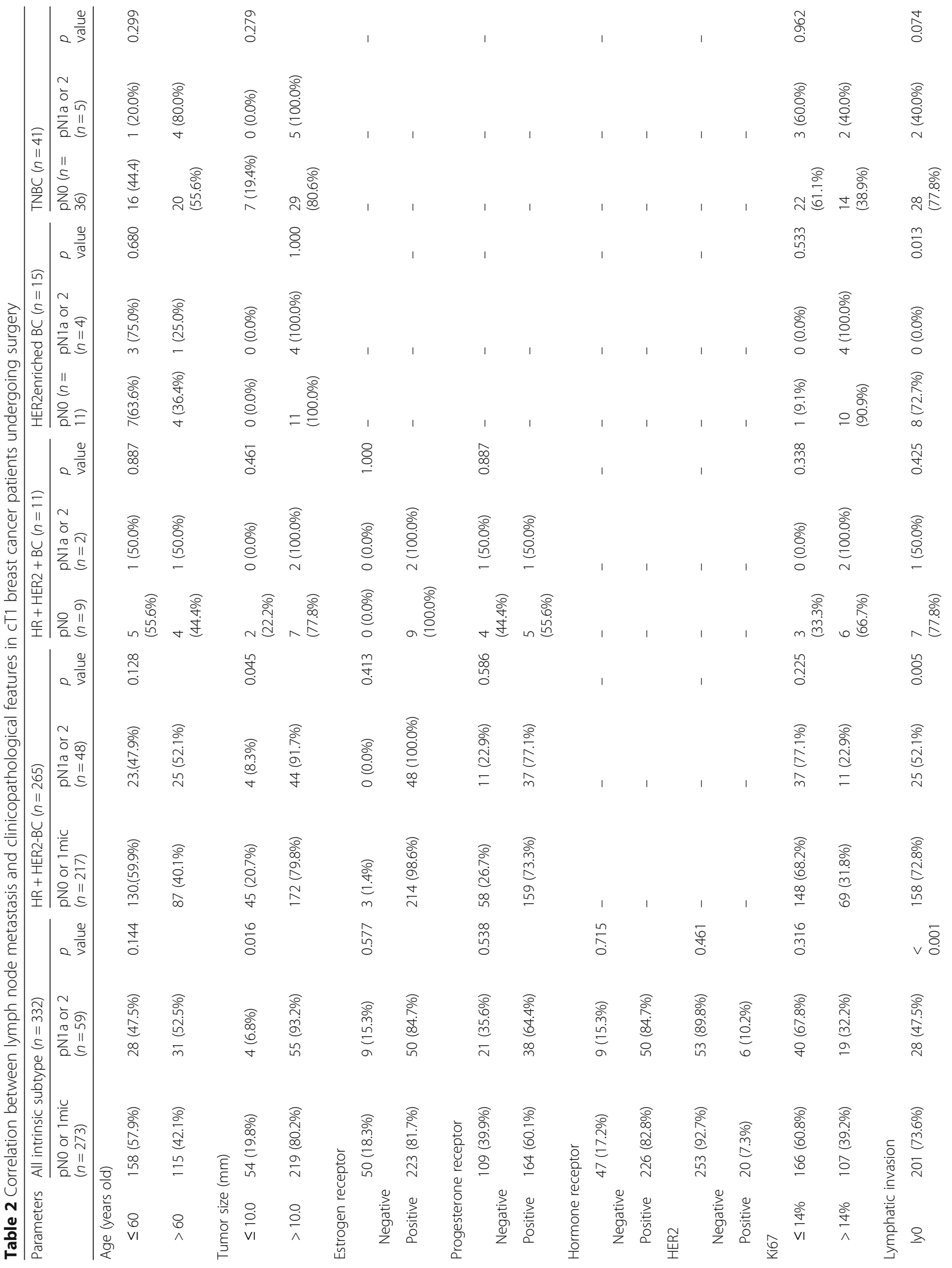




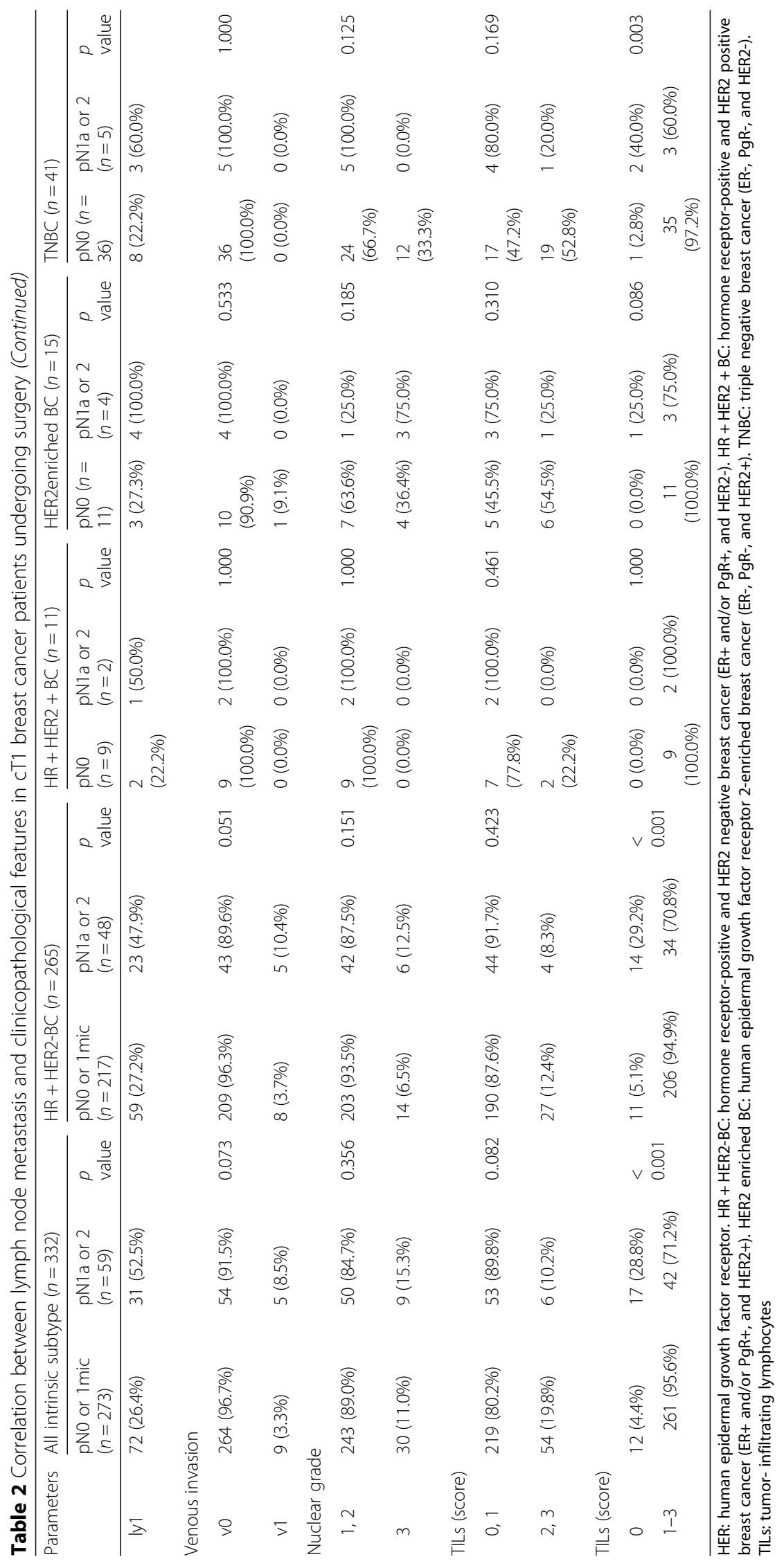




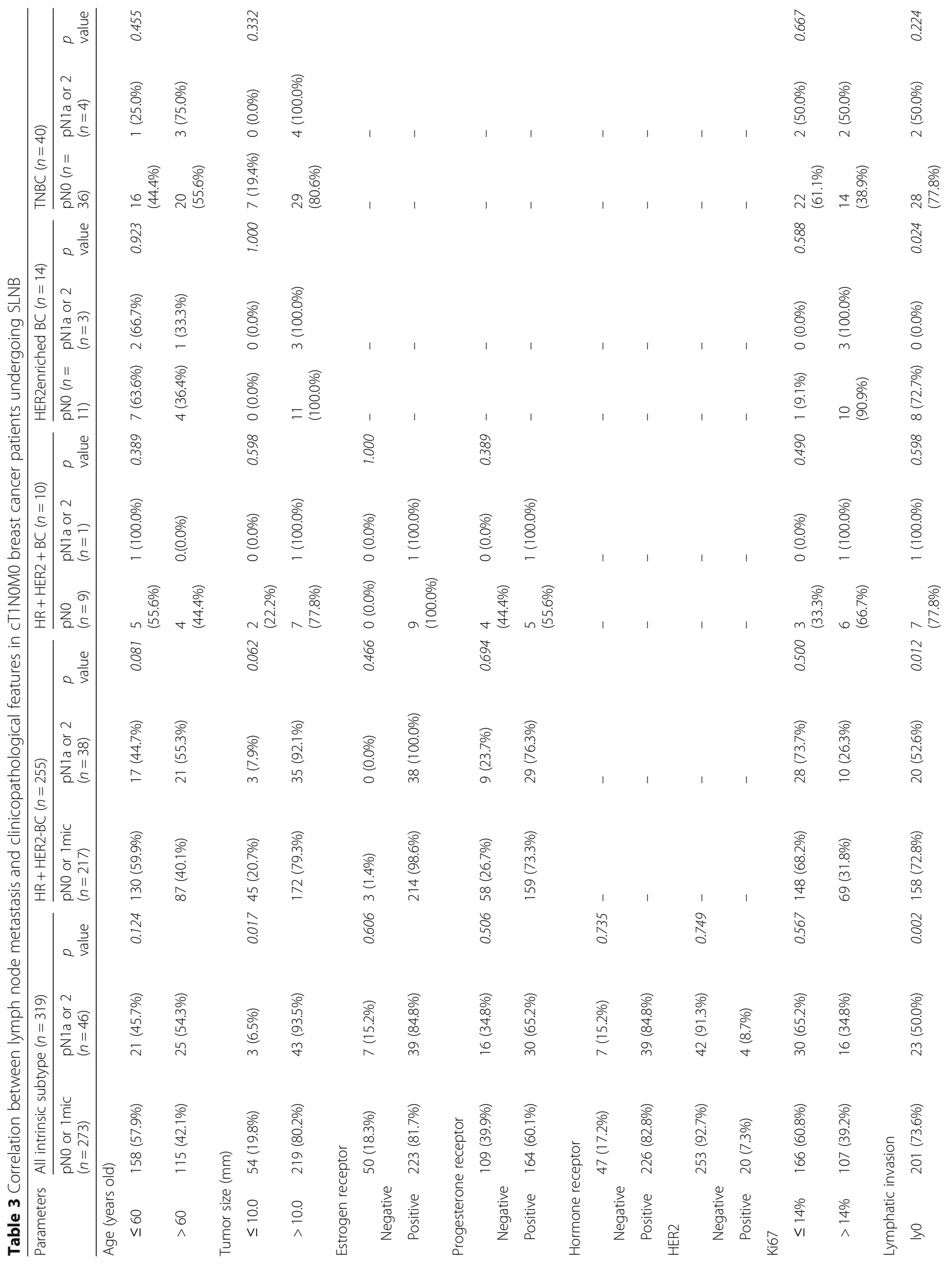




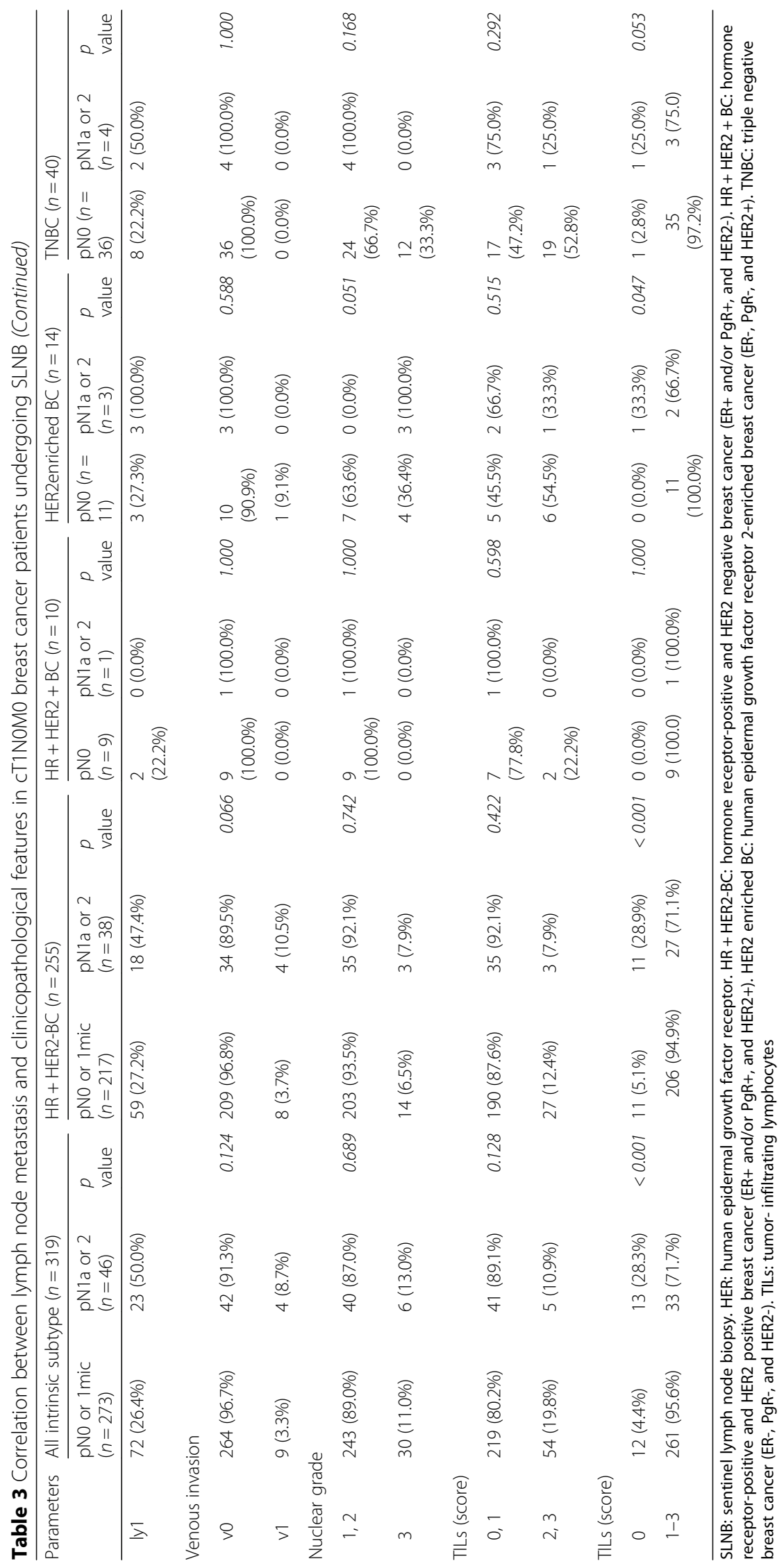


Table 4 Correlation between TILs and clinicopathological features in CT1N0M0 breast cancer patients undergoing SLNB

\begin{tabular}{|c|c|c|c|c|c|c|}
\hline \multirow[t]{2}{*}{ Parameters } & \multicolumn{6}{|c|}{ tumor- infiltrating lymphocytes $(n=319)$} \\
\hline & Score $0(n=25)$ & Score 1-3 $(n=294)$ & $p$ value & Score $0,1(n=260)$ & Score 2, $3(n=59)$ & $p$ value \\
\hline \multicolumn{7}{|l|}{ Age (years old) } \\
\hline$\leq 60$ & $10(40.0 \%)$ & $169(57.5 \%)$ & 0.091 & $144(55.4 \%)$ & $35(59.3 \%)$ & 0.582 \\
\hline$>60$ & $15(60.0 \%)$ & $125(42.5 \%)$ & & $116(44.6 \%)$ & $24(40.7 \%)$ & \\
\hline \multicolumn{7}{|l|}{ Tumor size (mm) } \\
\hline$\leq 10.0$ & $1(4.0 \%)$ & $56(19.0 \%)$ & 0.059 & 49 (18.8\%) & $8(13.6 \%)$ & 0.339 \\
\hline$>10.0$ & $24(96.0 \%)$ & $238(81.0 \%)$ & & $211(81.2 \%)$ & $51(86.4 \%)$ & \\
\hline \multicolumn{7}{|l|}{ Estrogen receptor } \\
\hline Negative & $3(12.0 \%)$ & $54(18.4 \%)$ & 0.425 & $29(11.2 \%)$ & $28(47.5 \%)$ & $<0.001$ \\
\hline Positive & $22(88.0 \%)$ & $240(81.6 \%)$ & & $231(88.8 \%)$ & $31(52.5 \%)$ & \\
\hline \multicolumn{7}{|c|}{ Progesterone receptor } \\
\hline Negative & $9(36.0 \%)$ & $116(39.5 \%)$ & 0.734 & $88(33.8 \%)$ & $37(62.7 \%)$ & $<0.001$ \\
\hline Positive & $16(64.0 \%)$ & $178(60.5 \%)$ & & $172(66.2 \%)$ & $22(37.3 \%)$ & \\
\hline \multicolumn{7}{|l|}{ Hormone receptor } \\
\hline Negative & $3(12.0 \%)$ & $51(17.3 \%)$ & 0.494 & 27 (10.4\%) & $27(45.8 \%)$ & $<0.001$ \\
\hline Positive & $22(88.0 \%)$ & $243(82.7 \%)$ & & $233(89.6 \%)$ & $32(54.2 \%)$ & \\
\hline \multicolumn{7}{|l|}{ HER2 } \\
\hline Negative & $24(96.0 \%)$ & $271(92.2 \%)$ & 0.487 & $245(94.2 \%)$ & $50(84.7 \%)$ & 0.013 \\
\hline Positive & $1(4.0 \%)$ & $23(7.8 \%)$ & & $15(5.8 \%)$ & $9(15.35)$ & \\
\hline \multicolumn{7}{|l|}{ Ki67 } \\
\hline$\leq 14 \%$ & 19 (76.0\%) & $177(60.2 \%)$ & & $170(65.4 \%)$ & $26(44.1 \%)$ & \\
\hline$>14 \%$ & $6(24.0 \%)$ & $177(39.8 \%)$ & 0.119 & 90.(34.6\%) & $33(55.9 \%)$ & 0.002 \\
\hline \multicolumn{7}{|c|}{ Lymphatic invasion } \\
\hline ly0 & 19 (56.0\%) & $210(71.4 \%)$ & 0.105 & $182(70.0 \%)$ & $42(71.2 \%)$ & 0.857 \\
\hline ly1 & $11(44.0 \%)$ & $84(28.6 \%)$ & & 78 (30.0\%) & $17(28.8 \%)$ & \\
\hline \multicolumn{7}{|l|}{ Venous invasion } \\
\hline vo & $25(100.0 \%)$ & $281(95.6 \%)$ & 0.283 & $252(96.9 \%)$ & $54(91.5 \%)$ & 0.058 \\
\hline $\mathrm{v} 1$ & $0(0.0 \%)$ & $13(4.4 \%)$ & & $8(3.1 \%)$ & $5(8.5 \%)$ & \\
\hline \multicolumn{7}{|l|}{ Nuclear grade } \\
\hline 1,2 & $24(96.0 \%)$ & $259(88.1 \%)$ & & $236(90.8 \%)$ & 47 (79.7\%) & \\
\hline 3 & $1(4.0 \%)$ & 35 (11.9\%) & 0.230 & $24(9.2 \%)$ & $12(20.3 \%)$ & 0.015 \\
\hline \multicolumn{7}{|c|}{ Pathological lymph node metastasis } \\
\hline $\mathrm{pNO} / \mathrm{pN} 1 \mathrm{mic}$ & $12(48.0 \%)$ & $261(88.8 \%)$ & & $219(84.2 \%)$ & $54(91.5 \%)$ & \\
\hline pN1a / pN2 & $13(52.0 \%)$ & $33(11.2 \%)$ & $<0.00121$ & $41(15.8 \%)$ & $5(8.5 \%)$ & 0.150 \\
\hline
\end{tabular}

TLL tumor- infiltrating lymphocytes, SLNB sentinel lymph node biopsy, HER human epidermal growth factor receptor

logistic regression model. P-values less than 0.05 were considered significant.

\section{Ethics statement}

This study was conducted at Osaka City University, Osaka, Japan, and conducted in accordance with the Declaration of Helsinki. The study protocol was approved by the Ethics Committee of Osaka City University (approve number: \#926). All patients were informed of the investigational nature of this study and provided their written, informed consent.

\section{Results}

Clinicopathological features

Table 1 shows the clinicopathological features of 332 patients with cT1N0-2 M0 breast cancer who underwent surgery and 319 patients with cT1N0M0 breast cancer who underwent SLNB. Therefore, 13 patients (3.9\%) were diagnosed with axillary lymph node metastases on 


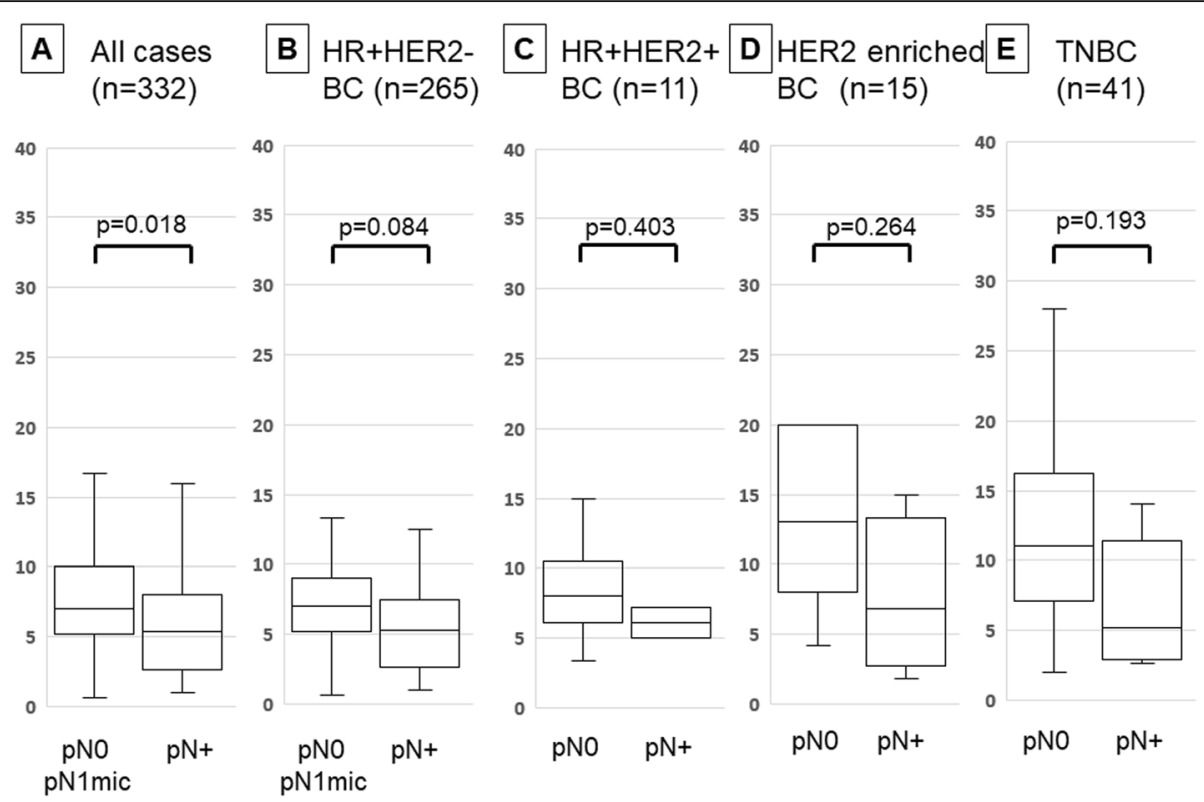

Fig. 2 Comparison of tumor-infiltrating lymphocyte (TIL) density by differences in lymph node metastasis by box-plot diagrams in CT1 breast cancer: all (a), HR + HER2-BC (b), HR + HER2 + BC (c), HER2-enriched BC (d), triple-negative breast cancer (e). Correlation was performed by Student's t test

imaging investigation (cN1: 11 patients (3.3\%), cN2: 2 patients( $(0.6 \%))$.In both groups, the median age was 59 (range, 29-79) years, and the median tumor diameter was $13 \mathrm{~mm}$ (range, $4.0-20.0 \mathrm{~mm}$ ). In patients with cT1N0M0 breast cancer, 262 patients $(82.1 \%)$ were positive for ER, 194 (60.8\%) were positive for PgR, and 24 (7.5\%) were positive for HER2. High Ki67 expression was observed in 123 patients (38.8\%). The following results were demonstrated by the intrinsic subtypes: $\mathrm{HR}+$ HER2-BC: 255 patients (79.9\%), HR + HER2 + BC: 10 patients (3.1\%), HER2-enriched BC 14 patients (4.4\%), TNBC: 40 patients (12.5\%). Pathologically, lymphatic invasion was observed in 95 patients (29.8\%), and venous invasion in 13 patients (4.1\%). Regarding the nuclear

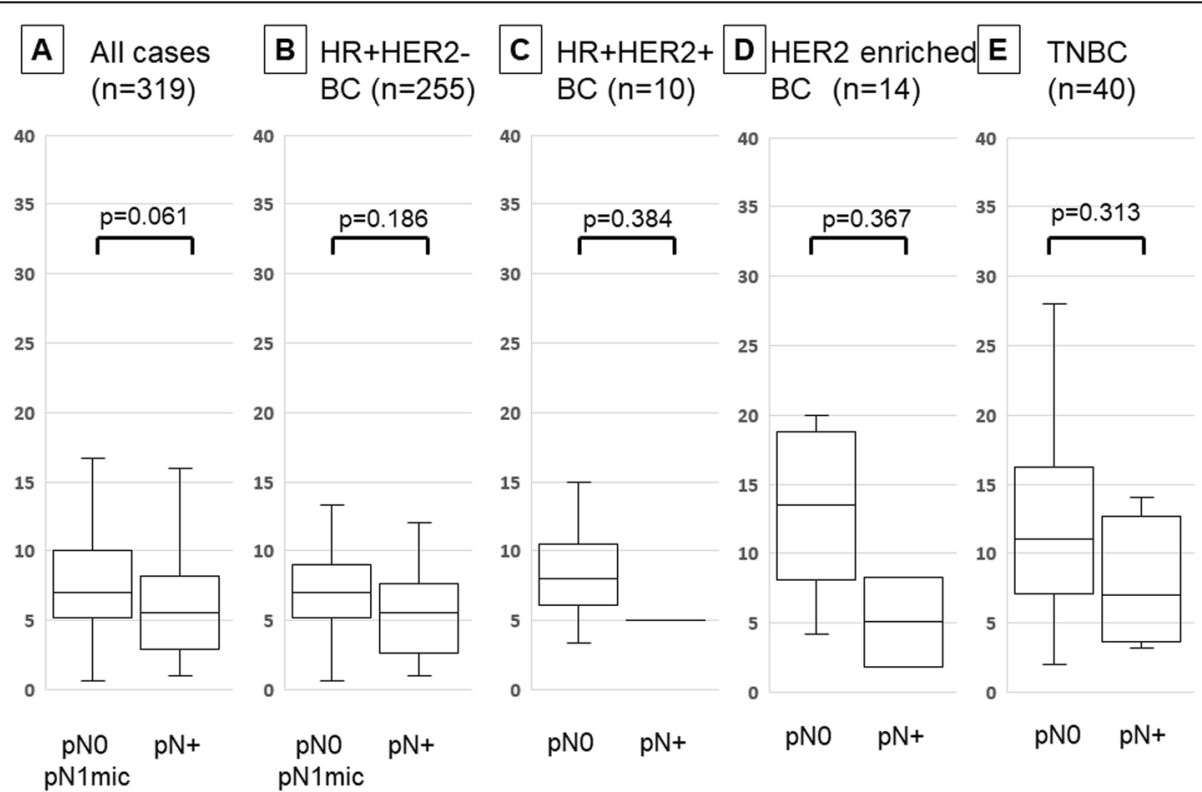

Fig. 3 Comparison of tumor-infiltrating lymphocyte (TIL) density by differences in lymph node metastasis by box-plot diagrams in cT1NOMO breast cancer patients undergoing SLNB: all (a), HR + HER2-BC (b), HR + HER2 + BC (c), HER2-enriched BC (d), triple-negative breast cancer (e). Correlation was performed by Student's t test 
grade, only 36 patients (11.3\%) were diagnosed with grade 3 . These results did not differ significantly when compared with the entire group of cT1 patients undergoing surgery.

For SLNB, a median of 2 (range, 1-8) SLNs were identified and evaluated pathologically. There were 60 cases (19.4\%) of SLNM (macrometastasis: 46 cases, micrometastasis: 16 cases). The intrinsic subtype of all breast cancers with micrometastasis was HR + HER2-BC. All patients who underwent axillary dissection due to lymph node metastasis on radiological examination had pathological metastasis to the lymph nodes.

When TIL densities were examined in the biopsied tissues, in cN0 cases, 25 patients (7.8\%) had score 0, 235 (73.7\%) had score 1, 56 (17.6\%) had score 2, and three $(0.9 \%)$ had score 3 . In the 13 cases in which lymph node metastasis was detected by imaging, four patients had score 0 , eight had score 1 , and one had score 2 .

\section{Correlation between clinicopathological features and lymph node metastasis}

The correlations between clinicopathological features and lymph node metastasis are listed in Table 2. Metastasis was significantly higher in breast cancers with tumor diameter $>10 \mathrm{~mm}$ than in those with diameter $\leq$ $10 \mathrm{~mm}(\mathrm{p}=0.016)$. Additionally, metastasis was significantly associated with lymphatic invasion $(\mathrm{p}<0.001)$. These two clinicopathological factors correlated with SLNM even in patients diagnosed with cNO (tumor size; $\mathrm{p}=0.017$, lymphatic invasion; $\mathrm{p}=0.002)$ (Table 3$)$.

Correlation between clinicopathological features and TILs We examined the correlation between clinicopathological features and TILs in cNO breast cancer cases (Table 4). When the patients were divided into TIL density score $0-1$ and score $2-3$, that is, a cut-off value of $10 \%$ was used for division into the higher group and lower group, the lower group correlated with the following clinicopathological factors; ER positive $(\mathrm{p}<0.001)$, PgR positive $(\mathrm{p}<0.001)$, HER2 negative $(\mathrm{p}=0.013)$, Ki67 high $(\mathrm{p}=0.002)$, nuclear grade high $(\mathrm{p}=0.015)$. However, if the patients were divided into TIL density score 0 and score $1-3$, that is, by the presence or absence of TIL density, correlation with these clinicopathological factors was not observed. When examined by intrinsic subtype, in HR + HER2-BC, patients with TILs density score 0 were significantly more aged $(p=0.035)$ and had a larger tumor size $(\mathrm{p}=0.020)$ than in patients with TILs density score 1-3 (Supplementary Table 1). In HER2enriched $\mathrm{BC}$, the frequency of venous invasion was significantly higher in patients with TILs density score 0 than in patients with TILs density score $1-3(\mathrm{p}=0.011)$. However, SLNM was significant in breast cancer with absent TIL density $(\mathrm{p}<0.001)$. When examined by intrinsic subtypes, HR + HER-2 BC and HER2-enriched BC significantly correlated with SLNM, and TNBC also showed a similar tendency (HR + HER2-BC: $\mathrm{p}<0.001$, HER2-enriched BC: $\mathrm{p}=0.047$, TNBC: $\mathrm{p}=0.053$ ) (Table $3)$.

TIL density was significantly lower in patients with lymph node metastasis than in those without it in all $\mathrm{cT} 1$ patients $(\mathrm{p}=0.018)$ (Fig. 2). When examined by intrinsic subtype, there was no significant difference between the subtypes. Moreover, no significant difference was observed in all cases when focusing on cNO cases $(\mathrm{p}=0.061)$ (Fig. 3).

Based on these results, multivariate analysis for SLNM predictors revealed that lymphatic invasion $(\mathrm{p}=0.008$, $\mathrm{OR}=2.522)$ and TILs $(\mathrm{p}<0.001$, OR $=0.137)$ were independent factors for prediction of SLNM (Table 5).

Table 5 Univariate and multivariate analysis with sentinel lymph node metastasis for CT1NOMO breast cancer

\begin{tabular}{|c|c|c|c|c|c|c|}
\hline \multirow[t]{2}{*}{ Parameters } & \multicolumn{3}{|c|}{ Univarite analysis } & \multicolumn{3}{|c|}{ Multivarite analysis } \\
\hline & Odd ratio & $95 \% \mathrm{Cl}$ & $p$ value & Odd ratio & $95 \% \mathrm{Cl}$ & $p$ value \\
\hline Age at operation (years old) $\leq 60$ vs $>60$ & 1.636 & $0.873-3.065$ & 0.124 & & & \\
\hline Tumor size $(\mathrm{mm}) \leq 10.0$ vs $>10.0$ & 3.534 & $1.056-11.825$ & 0.017 & 2.639 & $0.888-11.346$ & 0.085 \\
\hline Estrogen receptor Negative vs Positive & 1.249 & $0.528-2.955$ & 0.606 & & & \\
\hline Progesterone receptor Negative vs Positive & 1.246 & $0.648-2.395$ & 0.506 & & & \\
\hline Hormone receptor Negative vs Positive & 1.159 & $0.488-2.748$ & 0.735 & & & \\
\hline HER2 Negative vs Positive & 1.205 & $0.392-3.700$ & 0.749 & & & \\
\hline Ki67 $\leq 14 \%$ vs $>14 \%$ & 0.827 & $0.430-1.590$ & 0.567 & & & \\
\hline Lymphatic invasion ly0 vs ly 1 & 2.792 & $1.476-5.282$ & 0.002 & 2.522 & $1.280-4.973$ & 0.008 \\
\hline Venous invasion v0 vs v1 & 2.794 & $0.823-9.481$ & 0.124 & & & \\
\hline Nuclear grade 1, 2 vs 3 & 1.215 & $0.475-3.105$ & 0.689 & & & \\
\hline TILs 0,1 vs 2,3 & 0.495 & $0.187-1.311$ & 0.128 & & & \\
\hline TILs 0 vs $1-3$ & 0.117 & $0.049-0.277$ & $<0.001$ & 0.137 & $0.055-0.335$ & $<0.001$ \\
\hline
\end{tabular}

Cl confidence intervals, HER2 human epidermal growth factor receptor 2, TILs tumor- infiltrating lymphocytes 


\section{Discussion}

Numerous studies have reported predictors of SLNM. Although some studies have reported age [6-9], site [6, 10, 24], ER positivity [7, 24], PgR positivity [8, 24], HER2 positivity [25] as predictors of SLNM, the most commonly reported predictors are tumor size [6-10, 24, 25], lymphatic invasion $[6-8,24,25]$, and pathological nuclear grade $[6-10,24,25]$. In our study, the SLNM rate was similar to previous reports, and tumor size and lymphatic invasion were found to be predictive factors. However, intrinsic subtype and nuclear grade were not found to be predictors in our study. In recent years, it has been known that the pathological response to preoperative chemotherapy is a predictor of prognosis [2629]. Based on these reports, preoperative chemotherapy is actively administered in HER2-positive breast cancer and TNBC because the treatment response is greater than that in hormone receptor-positive breast cancer. As a result, the number of patients who underwent surgery primarily for HER2-positive breast cancer or TNBC was considered to be the reason for conducting this study.

After defining the cut-off value for TIL density as $10 \%$, as previously reported, hormone-positive breast cancer was observed to have lower TIL density while hormonenegative breast cancer or HER2-positive breast cancer were observed to have higher TIL density in this study $[13,14]$. When the correlation between TILs and clinicopathological factors was examined, in HR + HER2-BC, the correlations between TILs and tumor size or age were shown. Regarding the tumor size, it has recently been reported that the microenvironment around the cancer changes depending on the local progression [30]. According to the report, not only CD8 + lymphocytes that suppress cancer progression but also FOXP3positive lymphocytes that promote cancer progression are reduced. In other words, as cancer progresses, immune escape may begin to occur, and metastases are likely to occur accordingly. Regarding age, we have previously reported that young breast cancer patients tend to have higher TILs density (date not shown). That may have influenced the results in this time. This study suggests that the tumor immune-microenvironment is involved in lymph node metastasis. Our hypothesis was that the TIL density may be a predictor of SLNM. The correlation between TILs and lymph node metastasis has been reported in gastric cancer, melanoma, and breast cancer [31-33]. A study on breast cancer examined 76 patients who underwent surgery first and 96 patients who underwent preoperative chemotherapy, and it reported that there was a correlation between TILs and lymph node metastasis in both groups. Interestingly, Caziuc evaluated not only SLNs but also axillary lymph nodes in cases of additional axillary lymph node dissection due to SLNM. However, detailed analysis of the subtypes that could affect TIL density was not conducted, and no detailed data were provided on the relationship between TILs and clinicopathological factors. Furthermore, no relationship was found between any clinicopathological features other than TILs and lymph node metastasis. Accordingly, this report did not examine clinicopathological factors other than TILs, which are predictors of lymph node metastasis. However, our research is significant because we examined the correlation between TILs and clinicopathological factors such as all the subtypes and performed multivariate analysis to determine the predictors of SLNM, including TILs.

We are aware that our study has some limitations. Firstly, there were few HER2-positive breast cancer and TNBC patients, as we have stated earlier. Furthermore, there were a few cases with distant metastases along with a primary lesion of less than $20 \mathrm{~mm}$ that were excluded from our study. However, some studies have reported that TIL density is predictive of chemotherapy response [34, 35]. Therefore, if SLNB was omitted even if the SLN had metastasized in cNO breast cancer with high TIL density, postoperative chemotherapy would be expected to have a high therapeutic effect and not affect the prognosis.

\section{Conclusions}

Our study suggests a correlation between lymph node metastasis and the tumor immune-microenvironment in cT1 breast cancer cases. Moreover, TIL density may be a predictor of SLNM in breast cancer patients without lymph node metastasis on preoperative imaging.

\section{Supplementary information}

Supplementary information accompanies this paper at https://doi.org/10. 1186/s12885-020-07101-y.

Additional file 1: Supplementary Table 1. Correlation between TILS and clinicopathological features in CT1N0MO breast cancer patients undergoing SLNB by intrinsic subtype.

\section{Abbreviations \\ BC: Breast cancer; Cl: Confidence intervals; CT: Computed tomography; ER: Estrogen receptor; HER2: Human epidermal growth factor receptor 2; HR: Hormone receptor; OR: Odds ratio; PgR: Progesterone receptor; SLN: Sentinel lymph node; SLNB: Sentinel lymph node biopsy; SLNM: Sentinel lymph node metastasis; TILs: Tumor-infiltrating lymphocytes; TNBC: Triple-negative breast cancer; US: Ultrasonography; VAB: Vacuum- assisted biopsy}

\section{Acknowledgements}

We thank Yayoi Matsukiyo and Tomomi Okawa (Department of Breast and Endocrine Surgery, Osaka City University Graduate School of Medicine) for helpful advice regarding data management.

\section{Authors' contributions}

KT participated in the design of the study and drafted the manuscript. SK participated in the design of the study and manuscript editing. YA, WG, RK, AY, TM, MS and TT helped with study data collection and manuscript preparation. HF helped with study data collection and participated in its 
design. $\mathrm{KH}$ and $\mathrm{MO}$ conceived the study, and participated in its design and coordination and helped to draft the manuscript. All authors have read and approved the final manuscript.

\section{Funding}

This study was supported in part by Grants-in Aid for Scientific Research (KAKENHI, Nos. 17 K10559 and 19 K18067) from the Ministry of Education, Science, Sports, Culture and Technology of Japan. The funders had no role in the design of the study and collection, analysis, and interpretation of data and in writing the manuscript.

\section{Availability of data and materials}

The datasets used and/or analyzed during the current study are available from the corresponding author on reasonable request.

\section{Ethics approval and consent to participate}

A written informed consent to participate in the study was obtained from each subject in accordance with the declaration of Helsinki principles. Each patient or the patient's family was fully informed of the investigational nature of this study and provided their written, informed consent. The study protocol was approved by the Ethics Committee of Osaka City University (approve number \#926).

\section{Consent for publication}

\author{
Not applicable.
}

\section{Competing interests}

The authors declare that they have no competing interests.

\section{Author details}

${ }^{1}$ Department of Breast and Endocrine Surgery, Osaka City University Graduate School of Medicine, 1-4-3 Asahi-machi, Abeno-ku, Osaka 545-8585, Japan. ${ }^{2}$ Department of Gastrointestinal Surgery, Osaka City University Graduate School of Medicine, 1-4-3 Asahi-machi, Abeno-ku, Osaka 545-8585, Japan. ${ }^{3}$ Department of Scientific and Linguistic Fundamentals of Nursing, Osaka City University Graduate School of Nursing, 1-5-17 Asahi-machi, Abeno-ku, Osaka 545-0051, Japan.

Received: 20 April 2020 Accepted: 22 June 2020

\section{Published online: 26 June 2020}

\section{References}

1. Veronesi U, Paganelli G, Viale G, Luini A, Zurrida S, Galimberti V, Intra M, Veronesi P, Maisonneuve P, Gatti G, et al. Sentinel-lymph-node biopsy as a staging procedure in breast cancer: update of a randomised controlled study. Lancet Oncol. 2006;7(12):983-90.

2. Krag DN, Anderson SJ, Julian TB, Brown AM, Harlow SP, Costantino JP, Ashikaga T, Weaver DL, Mamounas EP, Jalovec LM, et al. Sentinel-lymphnode resection compared with conventional axillary-lymph-node dissection in clinically node-negative patients with breast cancer: overall survival findings from the NSABP B-32 randomised phase 3 trial. Lancet Oncol. 2010; 11(10):927-33.

3. Jozsa F, Ahmed M, Baker R, Douek M. Is sentinel node biopsy necessary in the radiologically negative axilla in breast cancer? Breast Cancer Res Treat. 2019;177(1):1-4.

4. Gentilini O, Botteri E, Dadda P, Sangalli C, Boccardo C, Peradze N, Ghisini R, Galimberti V, Veronesi P, Luini A, et al. Physical function of the upper limb after breast cancer surgery. Results from the SOUND (sentinel node vs. observation after axillary ultra-souND) trial. Eur J Surg Oncol. 2016;42(5):685-9.

5. Reimer T, Stachs A, Nekljudova V, Loibl S, Hartmann S, Wolter K, Hildebrandt G, Gerber B. Restricted axillary staging in clinically and Sonographically node-negative early invasive breast Cancer (c/iT1-2) in the context of breast conserving therapy: first results following commencement of the intergroup-sentinel-mamma (INSEMA) trial. Geburtshilfe Frauenheilkd. 2017; 77(2):149-57.

6. Capdet J, Martel P, Charitansky H, Lim YK, Ferron G, Battle L, Landier A, Mery E, Zerdoub S, Roche $H$, et al. Factors predicting the sentinel node metastases in T1 breast cancer tumor: an analysis of 1416 cases. Eur J Surg Oncol. 2009;35(12):1245-9.

7. Reyal F, Rouzier R, Depont-Hazelzet B, Bollet MA, Pierga JY, Alran S, Salmon RJ, Fourchotte V, Vincent-Salomon A, Sastre-Garau X, et al. The molecular subtype classification is a determinant of sentinel node positivity in early breast carcinoma. PLoS One. 2011;6(5):e20297.

8. Viale G, Zurrida S, Maiorano E, Mazzarol G, Pruneri G, Paganelli G, Maisonneuve $P$, Veronesi U. Predicting the status of axillary sentinel lymph nodes in 4351 patients with invasive breast carcinoma treated in a single institution. Cancer. 2005;103(3):492-500.

9. Ding J, Jiang $L$, Wu W. Predictive value of Clinicopathological characteristics for sentinel lymph node metastasis in early breast Cancer. Med Sci Monit. 2017;23:4102-8

10. Zhang Y, Li J, Fan Y, Li X, Qiu J, Zhu M, Li H. Risk factors for axillary lymph node metastases in clinical stage T1-2N0M0 breast cancer patients. Medicine (Baltimore). 2019;98(40):e17481.

11. Soysal SD, Tzankov A, Muenst SE. Role of the tumor microenvironment in breast Cancer. Pathobiology. 2015;82(3-4):142-52.

12. Hanahan D, Coussens LM. Accessories to the crime: functions of cells recruited to the tumor microenvironment. Cancer Cell. 2012;21(3):309-22.

13. Ohtani H, Mori-Shiraishi K, Nakajima M, Ueki H. Defining lymphocytepredominant breast cancer by the proportion of lymphocyte-rich stroma and its significance in routine histopathological diagnosis. Pathol Int. 2015 65(12):644-51.

14. Stanton SE, Adams S, Disis ML. Variation in the incidence and magnitude of tumor-infiltrating lymphocytes in breast Cancer subtypes: a systematic review. JAMA Oncol. 2016;2(10):1354-60.

15. Cheang MC, Chia SK, Voduc D, Gao D, Leung S, Snider J, Watson M, Davies S, Bernard PS, Parker JS, et al. Ki67 index, HER2 status, and prognosis of patients with luminal B breast cancer. J Natl Cancer Inst. 2009;101(10):736-50.

16. McMasters KM, Tuttle TM, Carlson DJ, Brown CM, Noyes RD, Glaser RL, Vennekotter DJ, Turk PS, Tate PS, Sardi A, et al. Sentinel lymph node biopsy for breast cancer: a suitable alternative to routine axillary dissection in multiinstitutional practice when optimal technique is used. J Clin Oncol. 2000; 18(13):2560-6.

17. Kashiwagi S, Onoda N, Asano Y, Kurata K, Noda S, Kawajiri H, Takashima T, Ohsawa M, Kitagawa S, Hirakawa K. Ambulatory sentinel lymph node biopsy preceding neoadjuvant therapy in patients with operable breast cancer: a preliminary study. World J Surg Oncol. 2015;13:53.

18. Lee A, Krishnamurthy S, Sahin A, Symmans WF, Hunt K, Sneige N. Intraoperative touch imprint of sentinel lymph nodes in breast carcinoma patients. Cancer. 2002;96(4):225-31.

19. Khanna R, Bhadani S, Khanna S, Pandey M, Kumar M. Touch imprint cytology evaluation of sentinel lymph node in breast cancer. World J Surg. 2011;35(6):1254-9

20. Houvenaeghel G, Nos C, Mignotte H, Classe JM, Giard S, Rouanet P, Lorca FP, Jacquemier J, Bardou VJ, Groupe des Chirurgiens de la Federation des Centres de Lutte Contre le C. Micrometastases in sentinel lymph node in a multicentric study: predictive factors of nonsentinel lymph node involvement--Groupe des Chirurgiens de la Federation des Centres de Lutte Contre le Cancer. J Clin Oncol. 2006;24(12):1814-22.

21. Salgado R, Denkert C, Demaria S, Sirtaine N, Klauschen F, Pruneri G, Wienert S, Van den Eynden G, Baehner FL, Penault-Llorca F, et al. The evaluation of tumor-infiltrating lymphocytes (TILs) in breast cancer: recommendations by an international TILs working group 2014. Ann Oncol. 2015;26(2):259-71.

22. Kashiwagi S, Asano Y, Goto W, Takada K, Takahashi K, Noda S, et al. Use of tumor-infiltrating lymphocytes (TILs) to predict the treatment response to eribulin chemotherapy in breast cancer. PLoS One. 2017;12(2):e0170634.

23. Ono M, Tsuda H, Shimizu C, Yamamoto S, Shibata T, Yamamoto H, et al. Tumor-infiltrating lymphocytes are correlated with response to neoadjuvant chemotherapy in triple-negative breast cancer. Breast Cancer Res Treat. 2012;132(3):793-805

24. Qiu PF, Liu JJ, Wang YS, Yang GR, Liu YB, Sun X, Wang CJ, Zhang ZP. Risk factors for sentinel lymph node metastasis and validation study of the MSKCC nomogram in breast cancer patients. Jpn J Clin Oncol. 2012;42(11): 1002-7.

25. Klar M, Foeldi M, Markert S, Gitsch G, Stickeler E, Watermann D. Good prediction of the likelihood for sentinel lymph node metastasis by using the MSKCC nomogram in a German breast cancer population. Ann Surg Oncol. 2009;16(5):1136-42.

26. Rastogi P, Anderson SJ, Bear HD, Geyer CE, Kahlenberg MS, Robidoux A, Margolese RG, Hoehn JL, Vogel VG, Dakhil SR, et al. Preoperative chemotherapy: updates of National Surgical Adjuvant Breast and bowel project protocols B-18 and B-27. J Clin Oncol. 2008;26(5):778-85. 
27. von Minckwitz G, Untch M, Blohmer JU, Costa SD, Eidtmann H, Fasching PA, Gerber B, Eiermann W, Hilfrich J, Huober J, et al. Definition and impact of pathologic complete response on prognosis after neoadjuvant chemotherapy in various intrinsic breast cancer subtypes. J Clin Oncol. 2012; 30(15):1796-804

28. Cortazar P, Zhang L, Untch M, Mehta K, Costantino JP, Wolmark N, Bonnefoi H, Cameron D, Gianni L, Valagussa P, et al. Pathological complete response and long-term clinical benefit in breast cancer: the CTNeoBC pooled analysis. Lancet. 2014;384(9938):164-72.

29. Bonnefoi H, Litiere S, Piccart M, MacGrogan G, Fumoleau P, Brain E, Petit T, Rouanet P, Jassem J, Moldovan C, et al. Pathological complete response after neoadjuvant chemotherapy is an independent predictive factor irrespective of simplified breast cancer intrinsic subtypes: a landmark and two-step approach analyses from the EORTC 10994/BIG 1-00 phase III trial. Ann Oncol. 2014;25(6):1128-36.

30. Eleni P, Minas S, Maria M, Evangelos T, Haralambos K, Eleni K. A standardized evaluation method for FOXP3+ Tregs and CD8+ T-cells in breast carcinoma: association with breast carcinoma subtypes, Stage and Prognosis. Anticancer Res. 2019;39(3):1217-32.

31. Kim JY, Kim CH, Lee Y, Lee JH, Chae YS. Tumour infiltrating lymphocytes are predictors of lymph node metastasis in early gastric cancers. Pathology. 2017:49(6):589-95.

32. Azimi F, Scolyer RA, Rumcheva P, Moncrieff M, Murali R, McCarthy SW, Saw RP, Thompson JF. Tumor-infiltrating lymphocyte grade is an independent predictor of sentinel lymph node status and survival in patients with cutaneous melanoma. J Clin Oncol. 2012;30(21):2678-83.

33. Caziuc A, Schlanger D, Amarinei G, Dindelegan GC. Can tumor-infiltrating lymphocytes (TILs) be a predictive factor for lymph nodes status in both early stage and locally advanced breast cancer? J Clin Med. 2019;8(4):545.

34. Adams S, Gray RJ, Demaria S, Goldstein L, Perez EA, Shulman LN, Martino S, Wang M, Jones VE, Saphner TJ, et al. Prognostic value of tumor-infiltrating lymphocytes in triple-negative breast cancers from two phase III randomized adjuvant breast cancer trials: ECOG 2197 and ECOG 1199. J Clin Oncol. 2014;32(27):2959-66.

35. Loi S, Michiels S, Salgado R, Sirtaine N, Jose V, Fumagalli D, KellokumpuLehtinen PL, Bono P, Kataja V, Desmedt C, et al. Tumor infiltrating lymphocytes are prognostic in triple negative breast cancer and predictive for trastuzumab benefit in early breast cancer: results from the FinHER trial. Ann Oncol. 2014;25(8):1544-50.

\section{Publisher's Note}

Springer Nature remains neutral with regard to jurisdictional claims in published maps and institutional affiliations.

Ready to submit your research? Choose BMC and benefit from:

- fast, convenient online submission

- thorough peer review by experienced researchers in your field

- rapid publication on acceptance

- support for research data, including large and complex data types

- gold Open Access which fosters wider collaboration and increased citations

- maximum visibility for your research: over $100 \mathrm{M}$ website views per year

At BMC, research is always in progress.

Learn more biomedcentral.com/submissions 